\title{
UBVRI PHOTOMETRY OF STARS IN TRAPEZIUM TYPE SYSTEMS
}

\author{
Josef Warman and Juan Eghevarría \\ Instituto de Astronomía \\ Universidad Nacional Autónoma de México
}

\begin{abstract}
RESUMEN
Presentamos datos fotométricos en el sistema UBVRI para 50 estrellas miembros de 14 sistemas múltiples tipo trapecio. Los diagramas color-magnitud y color-color indican la presencia de excesos ultravioletas, así como de un comportamiento anómalo en la parte infraroja del espectro. Estas anomalías son consistentes con las esperadas a partir de las edades dinámicas de los trapecios.
\end{abstract}

\section{ABSTRAGT}

We present UBVRI photometric data for 50 stars forming 14 systems of the trapezium type. Color-magnitude and color-color diagrams indicate the presence of ultraviolet excess and anomalous behavior in the infrared part of the spectrum. This is consistent with the dynamical ages for stars in trapezia.

\section{THE OBSERVATIONS}

Although trapezium type systems have shown to be extremely interesting objects from the dynamical point of view as well as from the standpoint of stellar evolution, very few data can be found in the literature regarding their colors or spectral types. Due to this, we started in the fall of 1973 an observing program designed to give information on the statistical properties of the colors and magnitudes of trapezia, rather than on the detailed features of any particular system.

For this purpose, a convenient sample was considered to be Ambartsumian's list of trapezia (Ambartsumian 1954), which contains 108 objects. Although we have measured now 99 out of the 108 trapezia, in this paper we shall consider only 14 of these systems, containing 50 stars. These 14 systems have the largest angular separation between components, thus avoiding the problems due to light contamination between neighboring stars. These problems were particularly serious for us, since the photometers available for our work were not de- signed primarily for observation of very close stars. Examination of the colors and magnitudes of these 50 stars should facilitate the understanding of systems in which light contamination between neighboring stars might present a problem.

All the observations were made at the Astronomical Observatory in San Pedro Martir, Baja California, of the National University of Mexico. The 84-cm reflecting telescope was used. UBVRI filters we used are such that no transformation is required to the system defined by Johnson. A 1P21 phototube was used for the UBV colors and RCA7102 for the $\mathrm{R}$ and I. Both tubes were cooled to dry ice temperature. The observations of the 99 systems were carried out in five observing seasons, from September 1973 through August 1975. Each trapezium was observed between 2 and 5 times, on different nights. Common standards were observed, so that different nights' observations could be tied together.

No attempt was made to obtain high precision photometry, so a compromise was made in the ratio between standard and program stars. The probable error of the measurements is $0.025 \mathrm{~m}$ (average per 
TABLE 1

PHOTOMETRY FOR 50 STARS IN TRAPEZIA

\begin{tabular}{rrrrrrr}
\hline AMB & \multicolumn{1}{c}{$\mathrm{m}_{\mathrm{v}}$} & B-V & \multicolumn{1}{c}{ U-V } & V-R & V-I & Notes \\
\hline 12A & 8.43 & 0.30 & -0.13 & 0.28 & 0.49 & 5,3 \\
B & 11.2 & 0.33 & 0.45 & 0.49 & 0.74 & \\
$\mathrm{~A}^{\prime}$ & 9.91 & 0.36 & 0.31 & 0.26 & 0.62 & \\
$\mathrm{~B}^{\prime}$ & 10.84 & 0.49 & 0.60 & 0.34 & 0.65 & \\
$15 \mathrm{~A}$ & 3.61 & -0.11 & -0.47 & -0.06 & -0.16 & 1,2 \\
$\mathrm{~B}$ & 10.29 & 0.30 & -0.56 & 0.03 & -0.12 & \\
$\mathrm{C}$ & 10.42 & 0.29 & -0.47 & 0.36 & 0.96 & \\
$\mathrm{D}$ & 8.66 & 1.08 & 1.93 & 0.81 & 1.40 & \\
$23 \mathrm{~A}$ & 6.20 & -0.01 & -0.27 & 0.13 & 0.14 & 2 \\
$\mathrm{~B}$ & 7.72 & 0. & -0.22 & 0.12 & 0.19 & \\
$\mathrm{C}$ & 9.82 & 0.13 & 0.24 & 0.09 & 0.30 & \\
$24 \mathrm{~A}$ & 7.42 & 0.11 & -0.13 & 0.10 & 0.16 & \\
$\mathrm{~B}$ & 11.53 & 0.28 & 0.52 & 0.24 & 0.56 & \\
$\mathrm{C}$ & 12.00 & 1.20 & 1.92 & 0.87 & 1.68 & \\
$\mathrm{Aa}$ & 13.66 & 1.09 & 1.94 & 1.01 & 1.59 & \\
$34 \mathrm{~A}$ & 7.42 & -0.17 & -0.48 & 0.02 & -0.08 & \\
$\mathrm{~B}$ & 9.20 & 0.05 & 0.01 & -0.39 & 0.16 & \\
$\mathrm{C}$ & 12.24 & 0.40 & 0.41 & 0.42 & 0.68 & \\
$\mathrm{D}$ & 7.79 & 0.02 & -0.01 & 0. & 0.14 & \\
$\mathrm{E}$ & 11.81 & 1.71 & 3.69 & 1.5 & 2.84 & \\
$42 \mathrm{~A}$ & 4.61 & -0.11 & -0.60 & -0.02 & -0.16 & 1,2 \\
$\mathrm{~B}$ & 9.28 & 0.80 & 0.26 & 0.24 & 0.49 & \\
$\mathrm{C}$ & 10.53 & 1.0 & 1.63 & 0.66 & 1.11 & \\
$44 \mathrm{~A}$ & 8.36 & 0.01 & -0.15 & 0.05 & -0.01 & \\
$\mathrm{~B}$ & 9.30 & 0.12 & 0.13 & -0.53 & -0.03 & \\
$\mathrm{C}$ & 12.37 & 0.35 & 0.21 & 0.19 & 0.28 & \\
& & & & & &
\end{tabular}

\begin{tabular}{|c|c|c|c|c|c|c|}
\hline AMB & $\mathrm{m}_{\mathrm{v}}$ & B-V & $\mathrm{U}-\mathrm{V}$ & V-R & V-I & Notes \\
\hline $\begin{array}{c}54 \mathrm{~A} \\
\mathrm{~B} \\
\mathrm{C} \\
\mathrm{D} \\
\mathrm{E}\end{array}$ & $\begin{array}{r}3.88 \\
8.04 \\
10.99 \\
9.63 \\
9.25\end{array}$ & $\begin{array}{r}0.22 \\
-0.04 \\
0.23 \\
0.11 \\
0.04\end{array}$ & $\begin{array}{l}-0.30 \\
-0.15 \\
-0.07 \\
-0.46 \\
-0.61\end{array}$ & $\begin{array}{r}0.32 \\
-0.52 \\
1.26 \\
0.26 \\
0.16\end{array}$ & $\begin{array}{r}0.47 \\
-0.28 \\
1.42 \\
0.26 \\
0.13\end{array}$ & 1 \\
\hline $\begin{array}{r}55 \mathrm{~A} \\
\mathrm{~B} \\
\mathrm{C}\end{array}$ & $\begin{array}{l}10.17 \\
10.43 \\
12.20\end{array}$ & $\begin{array}{l}0.42 \\
0.41 \\
0.42\end{array}$ & $\begin{array}{l}0.44 \\
0.43 \\
1.44\end{array}$ & $\begin{array}{l}0.18 \\
0.22 \\
0.85\end{array}$ & $\begin{array}{l}0.43 \\
0.47 \\
1.28\end{array}$ & \\
\hline $\begin{array}{r}60 \mathrm{~A} \\
\mathrm{~B} \\
\mathrm{C}\end{array}$ & $\begin{array}{r}9.23 \\
11.20 \\
10.67\end{array}$ & $\begin{array}{l}0.61 \\
0.54 \\
1.12\end{array}$ & $\begin{array}{l}0.48 \\
0.32 \\
1.96\end{array}$ & $\begin{array}{l}0.60 \\
0.44 \\
0.75\end{array}$ & $\begin{array}{l}0.92 \\
0.70 \\
1.39\end{array}$ & \\
\hline $\begin{array}{r}66 \mathrm{~A} \\
\mathbf{B} \\
\mathbf{C}\end{array}$ & $\begin{array}{r}6.61 \\
7.19 \\
10.22\end{array}$ & $\begin{array}{l}0.02 \\
0.03 \\
0.74\end{array}$ & $\begin{array}{r}-0.56 \\
-0.92 \\
0.78\end{array}$ & $\begin{array}{r}-0.13 \\
0.30 \\
0.74\end{array}$ & $\begin{array}{r}-0.27 \\
-0.16 \\
1.13\end{array}$ & 2 \\
\hline $\begin{array}{r}82 \mathrm{~A} \\
\mathrm{~B} \\
\mathrm{C} \\
\mathrm{D}\end{array}$ & $\begin{array}{r}4.67 \\
9.39 \\
11.26 \\
12.55\end{array}$ & $\begin{array}{r}-0.03 \\
0.21 \\
0.41 \\
-0.45\end{array}$ & $\begin{array}{l}-1.00 \\
-0.14 \\
-1.06 \\
-1.31\end{array}$ & $\begin{array}{l}0.13 \\
0.18 \\
0.14 \\
0.48\end{array}$ & $\begin{array}{l}0.14 \\
0.36 \\
0.49 \\
0.38\end{array}$ & $1,2,3,6,7,4$ \\
\hline $\begin{array}{r}88 \mathrm{~A} \\
\mathbf{B} \\
\mathbf{C}\end{array}$ & $\begin{array}{r}5.94 \\
11.90 \\
10.32\end{array}$ & $\begin{array}{r}-0.11 \\
0.67 \\
0.45\end{array}$ & $\begin{array}{r}-1.05 \\
0.06 \\
0.44\end{array}$ & $\begin{array}{l}0 . \\
0.82 \\
0.23\end{array}$ & $\begin{array}{r}-0.06 \\
1.31 \\
0.52\end{array}$ & 2 \\
\hline $\begin{array}{c}96 \mathrm{~A} \\
\mathrm{~B} \\
\mathrm{C}^{*} \\
\mathrm{D}\end{array}$ & $\begin{array}{r}6.75 \\
9.94 \\
13.29 \\
6.81\end{array}$ & $\begin{array}{r}-0.04 \\
0.26 \\
0.65 \\
-0.07\end{array}$ & $\begin{array}{r}-0.30 \\
0.38 \\
0.52 \\
-0.32\end{array}$ & $\begin{array}{l}0 . \\
0.23 \\
0.91 \\
0.06\end{array}$ & $\begin{array}{c}0 . \\
0.36 \\
1.35 \\
-0.03\end{array}$ & 2 \\
\hline
\end{tabular}

* This star was measured only once.

1. Primary of the system has been measured by Johnson $(1966 b)$.

2. One or more of the stars in this system appear in the catalogue of UBV (Blanco 1968).

single measurement) or better, depending on the color. This error was computed from the observed standards. Whenever possible we compared our results for the program stars with measurements (either photometric or photographic) of the same stars available in the literature. In those cases the agreement is consistent with the $0.025 \mathrm{~m}$ estimated error.

Table 1 gives the results of the photometry for the 50 stars. The first colum gives the number of the trapezium in Ambartsumian's list. The second indicates the component of the trapezium. Columns 3 through 7 give the observed visual magnitude and

3. One or more of the stars in this system appear in the S.A.O. catalogue.

4. Studied by Eggen (1963).

5. Studied by Markarian (1951).

6. Studied by Rubin (1962).

7. Studied by Mendoza (1958).

colors for each star. In some cases some stars had been measured previously and could be found in the literature. References are given in the notes to the table.

As we mentioned previously, we were looking for the statistical behavior of the colors and magnitudes of stars in trapezia. In order to compare stars belonging to different systems, it is necessary to compute the distance to each trapezium and obtain the intrinsic colors through unreddening. To do so, we looked in the literature for the best available spectral types for the primaries in each trapezium. Given the spectral type, we had a knowledge of 
the intrinsic $\mathrm{B}-\mathrm{V}$ color as well as the absolute visual magnitude of the primary star. We used both Schmidt-Kaler (Schmidt-Kaler 1965) and Johnson's (Johnson 1966a) results in order to calculate the excess $E_{B-v}$. To obtain $A_{v}$, we used the extinction law $A_{v} / E_{B-v}:=3.1$. Although there exist strong departures from the standard value $R=3.1$ (Johnson $1966 a$; Herbst 1975) this departure seems to be associated with the presence of nebulosity surrounding the trapezium, as in the case of Orion. An examination of the Palomar photographs for our trapezia did not show evidence of such clouds, hence we adopted the value $R=3.1$. The distance to the trapezium was computed solving for $d$ in the formula:

$$
\mathrm{m}_{\mathrm{v}}-\mathrm{M}_{\mathrm{v}}=\mathrm{A}_{\mathrm{v}}-5+5 \log d .
$$

By this method we determined the distance $d$ in parsecs, the visual extinction $A_{v}$ for all the stars in the trapezium, as well as the absolute magnitude of these stars. The intrinsic (unreddened) colors were obtained utilizing the ratios (Johnson 1963)

$$
\begin{aligned}
\mathrm{E}_{\mathrm{U}-\mathrm{V}} / \mathrm{E}_{\mathrm{B}-\mathrm{V}} & =1.72 \\
\mathrm{E}_{\mathrm{V}-\mathrm{R}} / \mathrm{E}_{\mathrm{B}-\mathrm{V}} & =1.01 \\
\mathrm{E}_{\mathrm{V}-\mathrm{I}} / \mathrm{E}_{\mathrm{B}-\mathrm{V}} & =2.26
\end{aligned}
$$

Table 2 shows the spectral types that were used for estimating distances and color excess $E_{B-v}$. First and second columns give Ambartsumian's list number and Aitken's catalogue number for each system. The third column gives the spectral type given in the literature for the primaries in each trapezium. The fourth column gives the spectral type and luminosity class that were adopted for our computation. Whenever we lacked information about luminosity class, class $\mathrm{V}$ was assumed, unless we had evidence supporting a different assumption. These cases are shown in parentheses. Fourth and fifth columns give $A_{v}$ and distances computed by the method described above.

TABLE 2

SPECTRAL TYPES AND LUMINOSITY CLASSES FOR THE PRIMARIES IN THE TRAPEZIA

\begin{tabular}{lllllll}
\hline AMB & ADS & & Sp. (comp) & Av & $\mathrm{d}(\mathrm{kpc})$ & Notes \\
\hline 12 & 1877 & B3, B, B0 & B3(III) & 1.58 & 0.97 & $7,4,3,6,1$ \\
15 & 2159 & B8, B8V & B8V & 0.03 & 0.05 & $7,8,2,3,1$ \\
23 & 3579 & B8III, B6V & B6V & 0.48 & 0.19 & $8,3,1$ \\
24 & 3684 & B9 & B9(V) & 0.59 & 0.18 & 7 \\
34 & 4962 & B8 & B8(V) & $\ldots$ & 0.26 & 7 \\
42 & 6205 & B8 & B8(V) & $\ldots .2$ & 0.08 & $7,8,1$ \\
44 & 6366 & B9 & B9(V) & 0.28 & 0.33 & 7 \\
54 & 11169 & B8p, B8Iap & B8Iap & 0.74 & 1.17 & 7,3 \\
55 & 11179 & & (B7V) & 1.74 & 0.6 & 9 \\
60 & 11421 & & (B3V) & 2.57 & 0.5 & 9 \\
66 & 13117 & B5V, B9 & (B5V) & 0.62 & 0.25 & $7,8,3,1$ \\
82 & 14526 & B0p, B3e, B1IV, B1e & B1(V) & 0.75 & 0.31 & $7,3,5,1,10$ \\
88 & 14969 & B0, BIb, B0Ib & B0Ib & 0.37 & 1.9 & $7,8,3,1$ \\
96 & 15679 & B9 & B9(V) & 0.12 & 0.17 & $7,2,3,8,1$ \\
\hline
\end{tabular}

1. HD Catalogue.

2. 'Wilson's Catalogue of Radial Velocities.

3. Abt's Catalogue of Radial Velocities.

4. S.A.O. Catalogue.

5. Studied by Rubin and Burley (1962).

6. Studied by Markarian (1951).

7. Ambartsumian's list of trapezia (Ambartsumian 1954).

8. UBV Photometry Catalogue (Blanco 1968).

9. Derived using the $Q$ method.

10. Studied by Mendoza (1958). 


\section{RESULTS AND DISGUSSION}

From a dynamical point of view, trapezium type configurations are rather unstable and their half-life is of the order of $10^{6}$ years. If a steady state situation exists, in which trapezia are created continuously, we should expect $10 \%$ of trapezia to have nuclear ages of the order of $10^{5}$ years. Hence, in the photometry, we should expect to observe features that are usually associated to young objects (perhaps some pre-main sequence). Figure 1 is a plot of the known spectral types versus those predicted by the photometry. We have plotted in the $\mathrm{X}$-axis the value of the quantity $Q$ (Johnson 1953)

$$
\mathrm{Q}=(\mathrm{U}-\mathrm{B})-0.72(\mathrm{~B}-\mathrm{V})
$$

computed for the known spectral types of the primaries of the trapezia (see Table 2) using Johnson's (1966) values of $U-B$ and $B-V$ for each spectral type. In the $\mathrm{Y}$ axis we have plotted the same quantity $Q$, but computed from the measured photometric values of $(U-B)$ and $(B-V)$ for the same stars. We notice that the photometry tends to predict earlier spectral types than the ones obtained from the spectra. This result is independent of reddening, since $Q$ does not depend on reddening. We have also plotted in the graph the corresponding quantities for three stars (A, C and D) in the Orion Trapezium, which also fall above the $45^{\circ}$ line. Pho-

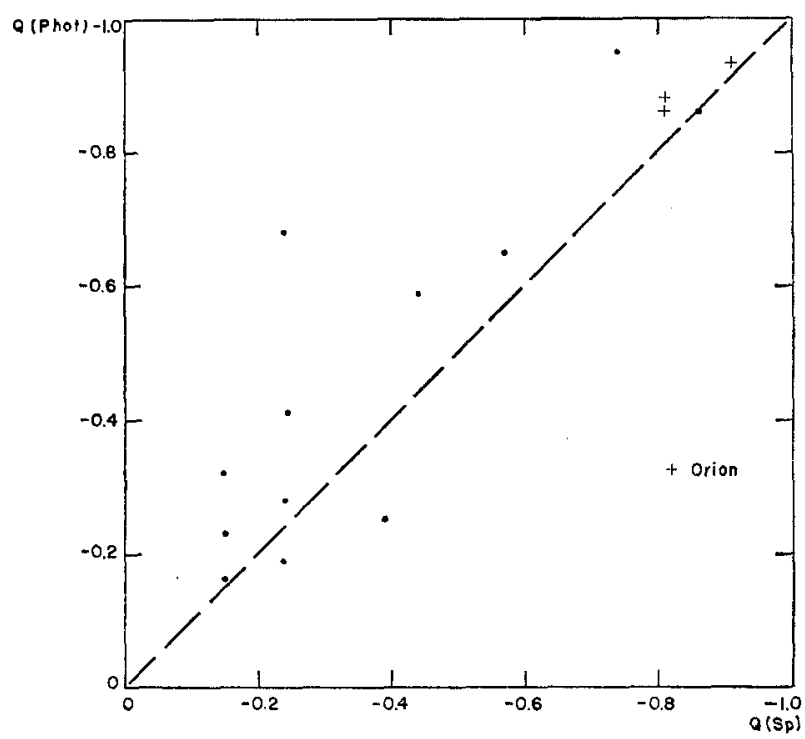

Fig. 1. Relation between known spectral types and those estimated from the photometry.

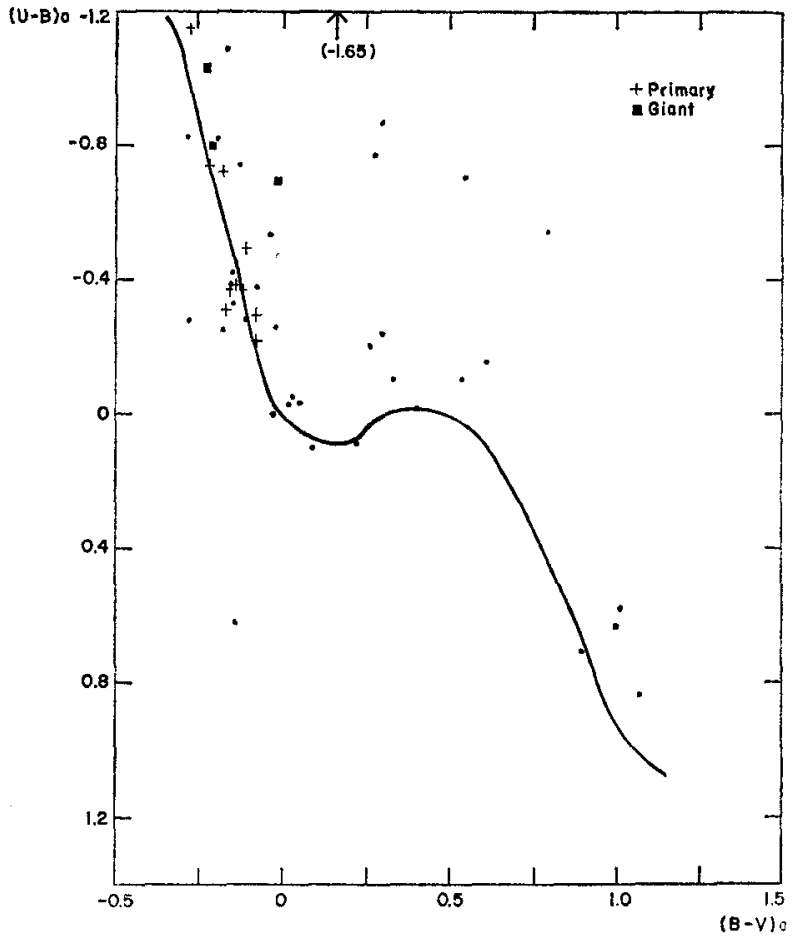

Fig. 2. Plot $(U-B)$ versus $(B-V)$.

tometry for these was taken from Johnson and Borgman (Johnson and Borgman 1963). The fact that the photometric $Q$ is systematically earlier than the spectral $Q$ indicates an anomalous behavior of the color indices. Figure 2 shows the intrinsic $(U-B)$ vs. $(\mathrm{B}-\mathrm{V})$ diagram for the 50 stars in the trapezia, unreddened by the method described previously. Crosses represent the primary stars. We notice the large scatter above the continuous curve. This curve was taken from Johnson for the main-sequence. Again, the anomalous behavior of the color indices is clear.

Figure 3 shows the color-magnitude diagram for the 50 stars. The continuous curve was taken from Schmidt-Kaler for the absolute magnitude of mainsequence stars. Crosses represent the primaries of trapezia. We notice the large scatter above and below the main-sequence. In fact, quite a few stars seem to lie more than half a magnitude below the main-sequence. We remark that the determination of the absolute magnitudes of these stars is tied together to the other stars in the trapezia. That is, if one tries to relocate any point on the graph, the 


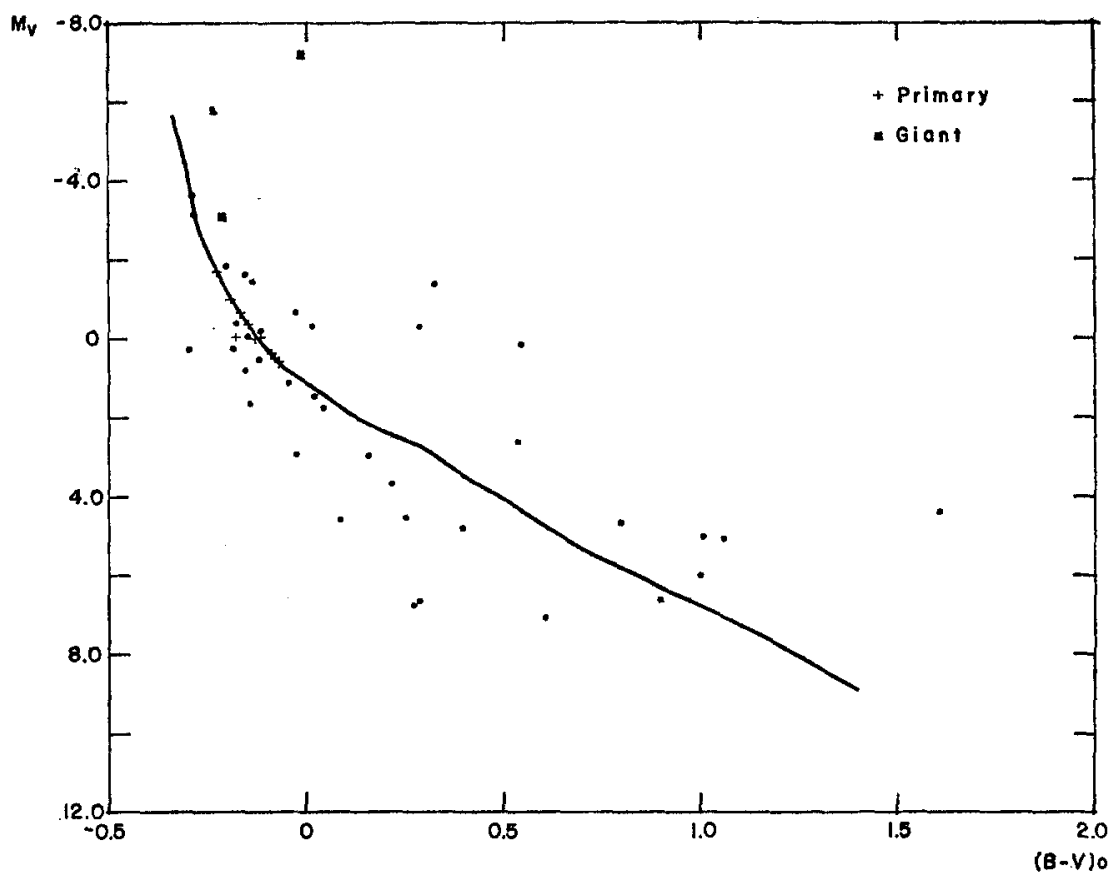

Fro. 3. Color magnitude diagram for 50 stars.

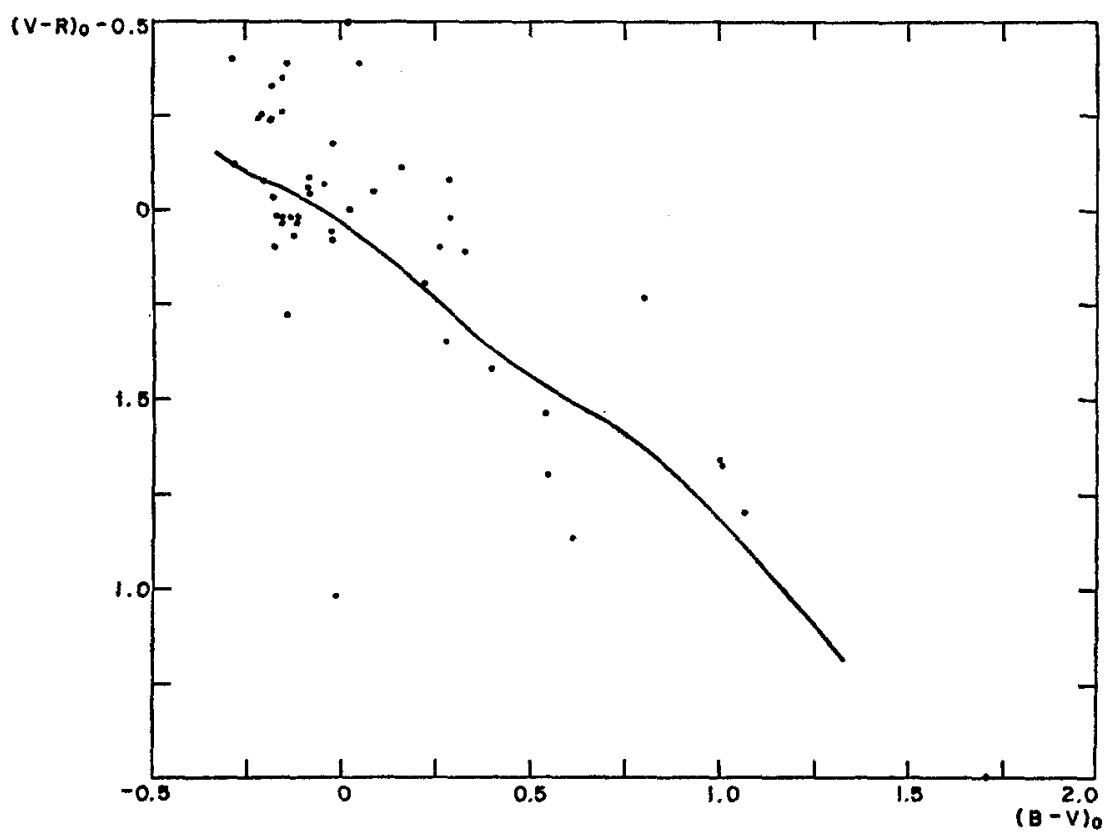

Fio. 4. Plot of $(V-R)$ versus $(B-V)$. 


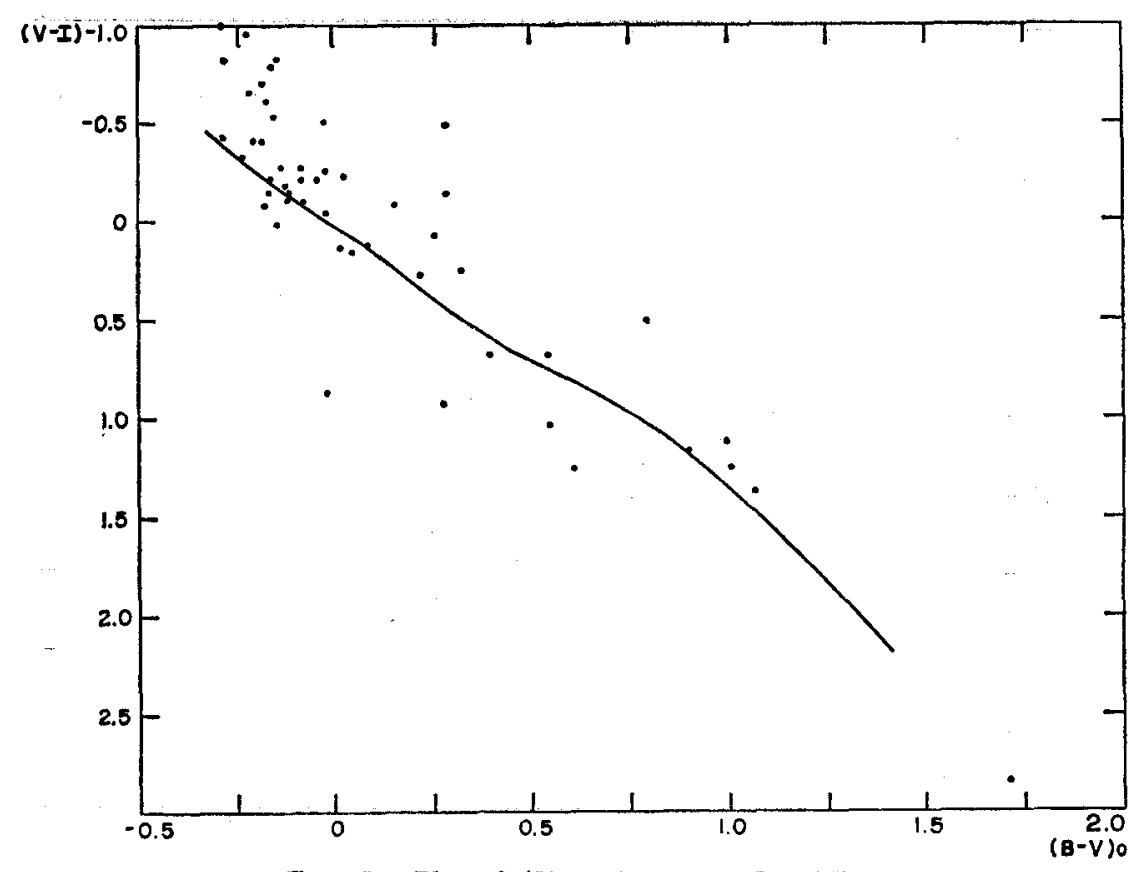

Fig. 5. Plot of $(V-I)$ versus $(B-V)$.

rest of the stars in that trapezium have to be moved as well.

Figure 4 and 5 show the diagrams for $(V-R)$ vs. $(\mathrm{B}-\mathrm{V})$ and $(\mathrm{V}-\mathrm{I})$ vs. $(\mathrm{B}-\mathrm{V})$ respectively. Again, we notice a large scatter above and below the main-sequence.

Our data indicate that a large fraction of the stars forming trapezium-type systems shows ultraviolet excess and anomalous behavior in the infrared part of the spectrum. This would be consistent with the dynamical interpretation that stars in trapezia are, indeed, young objects some of which are still approaching the main-sequence and may be surrounded by circumstellar shells. We feel, however, that these indications should not be considered as final. The process of unreddening, which was based on the $(B-V)$ color index, might induce a large scatter in the red colors, particularly in the $(\mathrm{V}-\mathrm{I})$. The spectral types and luminosity classes that were used to estimate distances must be checked, as well as the spectral types of the rest of the stars. Also, observations that go farther into the infrared should allow to make meaningful bolometric corrections and place the stars in a theoretical HR diagram. This work is now in progress.

\section{REFERENGES}

Ambartsumian, V. A. 1954, Contr. Obs. Byurakan, 15, 3. Blanco, V. M. Demers, S., Douglas, G. G. and Fitzgerald, M. P. 1968, Pub. U.S. Naval Obs., Second Series, 21. Eggen, O. J. 1963, A.J., 68, 483.

Herbst, W. 1975, A.J., 80, 498.

Johnson, H. L. 1966a, Ann. Rev. Astr. and Ap., 4, 197. Johnson, H. L., and Borgman, J. 1963, Bull. Astr. Inst. Netherl., 17, 115.

Johnson, H. L., and Morgan, W. W. 1953, Ap.J., 117, 313. Johnson, H. L., Mitchell, R. E., Iriarte, B., and Wisniewski, W. Z. 1966b, Comm. Lunar and Planet. Lab., 4, 99. Markarian, B. E. 1951, Contr. Obs. Byurakan, 9, 1.

Mendoza, E. 1958, Ap.J., 128, 207.

Rubin, V. C., and Burley, J. 1962, A.J., 67, 491.

Schmidt-Kaler, T. 1965, Astronomie und Astrophysik, ed. H. H. Voigt, (Heidelberg: Springer-Verlag), 284.

\section{DISGUSSION}

Scarfe: Do I understand that the points in the $(U-B),(B-V)$ diagram are corrected for reddening and therefore indicate large ultraviolet excesses in some cases?

Warman: That is correct. Knowing the spectral type of the primary star, we applied the same reddening to the ather stars, members of the trapezia, and there seems to be a large proportion of stars with UV excess. 